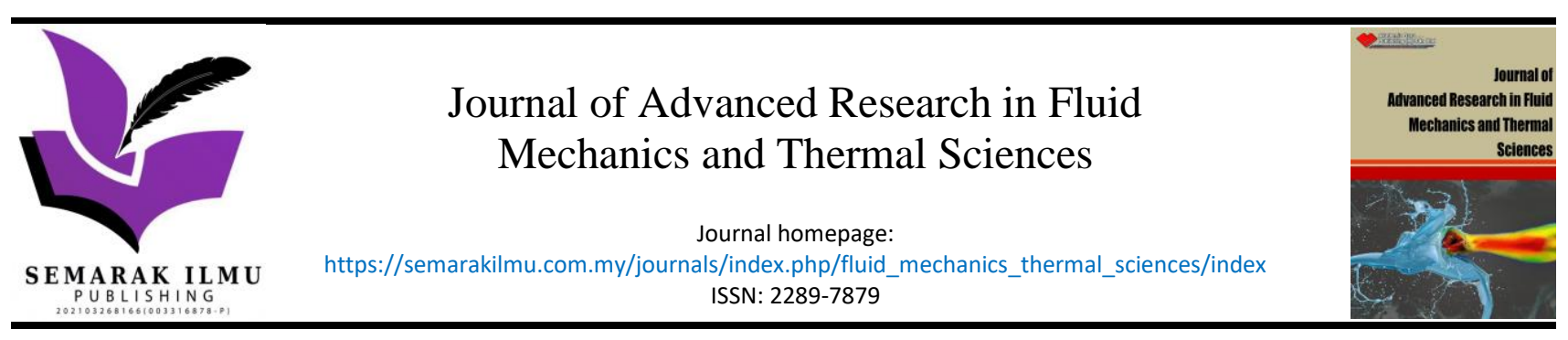

\title{
Investigating the Palm Oil Mill Wastes Properties for Thermal Power Plants
}

\author{
Noraishah Shafiqah Yacob ${ }^{1,}{ }^{*}$, Hassan Mohamed ${ }^{1}$, Abd Halim Shamsuddin $^{1}$ \\ 1 Institute of Sustainable Energy (ISE), Universiti Tenaga Nasional, 43000 Kajang, Selangor, Malaysia
}

ARTICLE INFO

\section{Article history:}

Received 28 June 2021

Received in revised form 10 September 2021

Accepted 19 September 2021

Available online 25 October 2021

\section{Keywords:}

Palm oil wastes; biomass; coal; empty fruit bunch (EFB); mesocarp fiber; palm kernel shell (PKS); thermal power plants; co-firing; renewable energy

\section{ABSTRACT}

\begin{abstract}
Renewable energy is a reliable solution for addressing global warming and fossil fuel depletion issues. Due to the abundance of biomass resources, such as palm oil wastes, which are currently underutilised, this is an opportunity for Malaysia to seize and implement this renewable energy solution for power generation. Palm oil mill wastes, such as empty fruit bunch (EFB), palm mesocarp fibre (PMF), and palm kernel shell (PKS), are worth to be investigated as a possible feedstock for combustion in thermal power plants. Co-combustion or co-firing of biomass in coal-fired thermal power plants offers a significant potential to reduce harmful emissions and represents a low cost and low-risk method. This paper aims to review and compare existing biomass thermal combustion technologies globally to evaluate the potential of utilising palm oil waste with coal. Before undergoing various pretreatment options, it is necessary to understand the feedstock characteristics for thermal power plant combustion. It is recommended to implement the combustion of palm oil wastes with coal in Malaysia to reduce harmful pollution. Based on the findings, Malaysia appears to be on the right track to optimise the use of palm oil wastes for electricity generation. The enhanced usage will reduce the negative impact of greenhouse gas (GHG) emissions.
\end{abstract}

\section{Introduction}

Nowadays, climate change is one of the most pressing environmental issues facing humankind globally. According to The Fifth Assessment Report (AR5), carbon dioxide $\left(\mathrm{CO}_{2}\right)$ emissions from industrial processes and fossil fuel combustion contributed about $78 \%$ to the overall rise in greenhouse gas (GHG) emissions between 1970 and 2010, with a relative percentage contribution over the period 2000 to 2010 [1]. Moreover, the depletion of fossil fuels and the effects of global warming encourages the optimizations of renewable energy resources. As a result, the International Energy Agency (IEA) forecasts that biomass will continue to be the most dominant and leading renewable energy resource between 2020 and 2035 [2].

Malaysia is blessed with abundant biomass resources, one of the most potential renewable energy candidates to overcome the issues mentioned above. Around 168 million tons of biomass are

\footnotetext{
* Corresponding author.

E-mail address: noraishah.shafiqah@uniten.edu.my
}

https://doi.org/10.37934/arfmts.88.2.113 
produced in Malaysia, including palm oil waste, rice husks, sugar cane waste, coconut waste, forestry waste, and municipal waste [3]. As the world's second-largest producer of palm oil, Malaysia has immense potential resources from biomass. Table 1 clearly shows that Malaysia has produced around 19,900 million tons or $26 \%$ of the world's palm oil production in 2020 , according to data from the United States Department of Agriculture [4]. On the other hand, Indonesia is still leading with 43,500 million tons of palm oil production, followed by Malaysia, Thailand, Colombia, and Nigeria.

Table 1

Palm oil production by country in 1000 MT (2020) [4]

\begin{tabular}{lll}
\hline Rankings & Country & Production (1000 MT) \\
\hline 1 & Indonesia & 43,500 \\
2 & Malaysia & 19,900 \\
3 & Thailand & 3,100 \\
4 & Colombia & 1,600 \\
5 & Nigeria & 1,280 \\
6 & Other & 6,083 \\
\hline
\end{tabular}

Palm oil mills generate a large amount of biomass waste. Hence, more efforts should be made to optimize the utilisation of biomass in thermal power plants. About $72 \%$ weight of the fresh fruit bunches (FFB) from palm oil waste is left as residues in solid form after the oil extraction [5]; these residues are empty fruit bunch (EFB), palm mesocarp fiber (PMF), and palm kernel shell (PKS). After the FFB has been pressurized, cooked, and stripped from the bunch for the oil extraction, it will produce the EFB. While PMF is produced in the palm oil extraction process, and PKS is obtained after separating the nut from the kernel [6]. Palm oil mill effluent (POME) is another valuable palm oil waste that comes in a liquid form produced at mill sites.

On the other hand, a dedicated coal combustion system is the preferred method because it has played a significant role in power generation. Furthermore, due to the differences in characteristics between coal and biomass, coal is much easier to handle and combust [7]. Additionally, compared to coal, biomass has lower heating values and bulk densities, requiring much more fuel to be transported and handled, resulting in a high investment.

However, electricity generation from dedicated coal-fired power plants continues to raise environmental concerns globally. These issues can be addressed by combining coal and biomass fuel for energy generation in existing coal-fired power plants $[8,9,13]$. In addition, coal can reduce the effects of variances in biomass if there is limited biomass feedstock.

As a result, in Malaysia, where biomass such as palm oil waste is abundant, it is a great opportunity to use the waste as a source of feedstock [4]. Furthermore, with the rapid depletion of fossil fuel reserves, the combustion of oil palm residues in the thermal power plant is a cost-effective option in general. More importantly, the substitution of coal with biomass for combustion will help to reduce $\mathrm{CO}_{2}$ emissions.

Some combustion consequences need to be identified and clearly understood regarding the fuel characteristics for biomass combustion with coal, specifically the solid palm oil wastes. The experience of utilities following various combustion technology for biomass utilisation is useful to consider in this work. Therefore, this paper aims to review and compare existing biomass thermal combustion technologies globally to evaluate the potential of utilizing palm oil waste with coal. 


\section{Operational Experience in Other Countries}

Co-firing biomass is a promising economic and environmental choice for power generation. It is a low-risk option for renewable energy production, compared with other alternative uses of biomass in terms of the cost of raw material supply and major capital investments [9]. In addition, co-firing can reduce biomass waste and environmental issues related to its disposal.

In addition, since biomass contains less nitrogen and sulfur than coal, co-firing coal with biomass has the capability to reduce nitrogen oxide $(\mathrm{NO})$ and sulphur dioxide $\left(\mathrm{SO}_{2}\right)$ emissions [12]. The success of reducing fossil $\mathrm{CO}_{2}$ emissions is largely due to the substitution of coal with renewable sources in co-firing [8-12]. Consequently, some major countries globally, especially in European countries, have vigorously developed large-scale co-firing coal and biomass for power generation [9].

There are three main methods of utilising biomass wastes for co-firing coal-biomass power generation $[8,10,12,21]$; (i) Direct co-firing, the best approach of co-firing, where biomass is fed directly into the furnace alongside coal. This method is also known as direct injection. (ii) In-direct co-firing involves advanced gasification of biomass in a separate gasifier. The biomass gas generated by gasification will be injected into a pulverized coal furnace for combustion. (iii) Parallel co-firing is the lowest risk method that requires installing a separate $100 \%$ biomass co-fired furnace to generate steam. The boilers used in co-firing technologies are typically determined by the current coal-fired or gas-fired combustion technologies.

For coal-fired power plants that are adopting co-firing the first time, co-firing by co-milling is the preferable method. Co-milling is the process of blending coal and biomass, which are then milled and combusted together. This method allows co-firing up to $5-10 \%$ heat input, but with some limitations on the ability of the coal mill to process biomass with coal [13]. However, this limitation can be overcome by pretreatment of biomass by torrefying or densifying it $[8,11,13]$.

This paper will review the existing co-firing biomass in some major European, North America, South America and Asia countries.

\subsection{European}

The European Union (E.U.) is well-known for being reliant on other countries for energy imports, particularly from Russia, which supplies $25.8 \%$ of solid fuels, $27.7 \%$ crude oil and $29.4 \%$ of natural gas in 2015 [14]. Nevertheless, the E.U. has pledged to reduce GHG emissions from 1990 to 2020 by 20\% and reach a further $80-95 \%$ reduction by 2050 [10]. In this section, a brief discussion of co-firing biomass technologies that are used in European countries. Table 2 below provides an overview of the current combustion and primary feedstocks used in the United Kingdom (U.K.), Netherlands, Germany and Denmark.

Table 2

Type of combustion and primary feedstocks in European countries [9]

\begin{tabular}{|c|c|c|}
\hline Country & Type of Combustion & Primary Feedstock \\
\hline United Kingdom & Direct co-firing & $\begin{array}{l}\text { Agricultural residues, energy crops, } \\
\text { forestry residues }\end{array}$ \\
\hline Netherlands & Direct and indirect co-firing & $\begin{array}{l}\text { Imported wood pellet, palm kernel } \\
\text { shells, wastes wood, cocoa shells }\end{array}$ \\
\hline Germany & $\begin{array}{l}\text { Direct (Fluidized bed: dry or wet } \\
\text { bottom) }\end{array}$ & $\begin{array}{l}\text { Sewage sludge, straw, waste wood, } \\
\text { organic residue }\end{array}$ \\
\hline Denmark & Direct and indirect co-firing & Straw, wood chips, wood pellets \\
\hline
\end{tabular}




\subsubsection{United Kingdom (U.K.)}

Co-firing has mainly played a transitional role on the road to increase renewable energy production in the United Kingdom (U.K.). However, investments in a diverse, low carbon and renewable energy scheme have become paramount as the U.K. aims to achieve lower GHG emissions and the increased output of renewable energy [9].

Biomass co-firing has been embraced by all of the U.K.'s main co-fired power plants. These plants consume $3 \%$ of biomass energy on average. Most plants started their co-firing experience with comilling and continue building a direct injection system for commercial production. Coal power plants in the U.K. have used various raw materials, including agricultural residues, energy crops and forestry residues. A list of the U.K.'s co-firing technology is listed in Table 3.

Table 3

Type of combustion, primary feedstocks, and operation status in U.K. [9]

\begin{tabular}{|c|c|c|c|}
\hline Number & Type of Combustion & Primary Feedstock & Operation status \\
\hline 1 & Direct injection & \multirow{14}{*}{$\begin{array}{l}\text { Wood pellets, } \\
\text { miscanthus, olive } \\
\text { residues, palm } \\
\text { residues }\end{array}$} & Limited Life Derogation \\
\hline 2 & Co-milling/indirect & & Limited Life Derogation \\
\hline 3 & Co-milling/direct injection & & Closed \\
\hline 4 & Co-milling/direct injection & & Closed \\
\hline 5 & Co-milling/direct injection & & Transitional National Plan \\
\hline 6 & Co-milling/direct injection & & Limited Life Derogation \\
\hline 7 & Direct injection & & Closed \\
\hline 8 & Direct injection & & Transitional National Plan \\
\hline 9 & Co-milling/direct injection & & Closed \\
\hline 10 & Co-milling/direct injection & & Closed \\
\hline 11 & Co-milling/direct injection & & Closed \\
\hline 12 & Direct injection & & Currently compliant \\
\hline 13 & Direct injection & & Transitional National Plan \\
\hline 14 & Co-milling/direct injection & & Closed \\
\hline
\end{tabular}

\subsubsection{Netherlands}

Combustion of biomass with coal is considered an important tool for meeting renewable energy targets in the Netherlands because of its growth potential. The most common co-firing method in the Netherlands is direct co-firing, primarily for wood pellets and coal. The Netherlands primarily uses wood pellets for co-firing. However, Netherlands imported most of their wood pellet resources because of the limited domestic resources available [9].

Besides, in the Netherlands, other co-firing resources include waste and demolition wood, cocoa shells, paper sludge, Malaysian palm kernel shells, olive kernel pulp, bio-oil, meat and bone meal, hydrocarbon gases and municipal waste [9]. Table 4 lists the type of combustion and primary feedstocks in the Netherlands. 
Table 4

Type of combustion and primary feedstocks in the Netherlands [9]

\begin{tabular}{|c|c|c|}
\hline Number & Type of Combustion & Primary Feedstock \\
\hline 1 & $\begin{array}{l}\text { Direct co-combustion with separate milling, injection } \\
\text { of pulverized wood in the pulverized fuel lines (pf- } \\
\text { lines) and simultaneous combustion }\end{array}$ & \multirow{8}{*}{$\begin{array}{l}\text { Imported wood } \\
\text { pellet, palm kernel } \\
\text { shells, wastes wood, } \\
\text { cocoa shells. }\end{array}$} \\
\hline 2 & $\begin{array}{l}\text { Direct co-combustion: separate dedicated milling } \\
\text { and combustion in dedicated biomass burners }\end{array}$ & \\
\hline 3 & $\begin{array}{l}\text { Direct co-firing: biomass is milled separately in } \\
\text { dedicated mills and combusted in separate burners }\end{array}$ & \\
\hline 4 & $\begin{array}{l}\text { Indirect co-firing: gasification in an atmospheric } \\
\text { circulating bed gasifier and co-firing of the fuel gas in } \\
\text { the coal-fired boiler }\end{array}$ & \\
\hline 5 & $\begin{array}{l}\text { Practice 1: direct co-firing by separate milling and } \\
\text { combustion Practice } 2 \text { : direct co-firing by mixing } \\
\text { with the raw coal before the mills }\end{array}$ & \\
\hline 6 & $\begin{array}{l}\text { Practice 1: direct co-firing of biomass, pulverized in a } \\
\text { separate hammer mill, injection into the pf-lines and } \\
\text { simultaneous combustion Practice } 2 \text { : liquid organics } \\
\text { fired in separate oil burners }\end{array}$ & \\
\hline 7 & Direct co-gasification & \\
\hline 8 & Direct co-firing of palm oil in dedicated burners & \\
\hline
\end{tabular}

\subsubsection{Germany}

Germany is recognized for its exceptional manufacturing performance and now adapting this efficiency to optimize energy use. Thirteen biomass co-firing power plants in Germany are based on mixed fuels, and approximately $50 \%$ of these facilities use sewage sludge for co-firing purposes [9]. Sewage sludge is primarily beneficial because of its negative cost and availability throughout the year. Straw, waste wood and organic residues are also some of Germany's other significant sources of biomass.

In comparison, although other European countries, such as the Netherlands, Denmark, UK, and Belgium, make the best use of wood pellets for co-fired purposes, the trend in Germany has not yet caught up, primarily due to its feed-in tariff policy for wood pellets. Table 5 shows that Germany mainly uses pulverized boilers when co-firing biomass with coal, depending on whether the ash is removed in a solid or molten state.

\section{Table 5}

Type of combustion and primary feedstocks in Germany [9]

\begin{tabular}{lll}
\hline Country & Type of Combustion & Primary Feedstock \\
\hline Germany & Direct (Fluidized bed: dry or & $\begin{array}{l}\text { Sewage sludge, straw, waste wood, } \\
\text { organic residue }\end{array}$ \\
(21 power stations) & wet bottom) & organ
\end{tabular}

\subsubsection{Denmark}

Denmark has set a very high standard with one of the world's most ambitious renewable energy targets. While primarily focused on wind energy, biomass plays a major role in eliminating the dependence on fossil fuels [9]. Denmark is one of the very few countries in Europe with experience in co-firing operations. There is a total of five co-firing installations in Denmark, listed in Table 6. 
Straw, wood chips and wood pellets are the main sources of biomass used in common co-firing power plants in Denmark. Among them, straw is the most popular because it is easily available on the domestic market.

Table 6

Type of combustion and primary feedstocks used in Denmark [9]

\begin{tabular}{lll}
\hline Number & Type of Combustion & Primary Feedstock \\
\hline 1 & $\begin{array}{l}\text { Direct co-combustion: separate feeding and } \\
\text { combustion in combined coal/straw burners }\end{array}$ & $\begin{array}{l}\text { Straw, wood chips, wood } \\
\text { pellets }\end{array}$ \\
\cline { 1 - 2 } 2 & $\begin{array}{l}\text { Indirect co-combustion: separate } \\
\text { combustion with steam-side integration }\end{array}$ \\
\cline { 1 - 2 } 3 & Direct combustion in the same furnace \\
\cline { 1 - 2 } 4 & Fluid-bed, mixed fuel \\
\hline 5 & Grate firing of biomass \\
\hline
\end{tabular}

\subsection{North America}

Developing alternate energy sources comes with its challenges. Due to high initial costs and a long return on investment, renewable energy in North America is less competitive [15]. Nonetheless, North America is still taking initiatives to reduce GHG emissions by reducing coal combustion, increasing the utilisation of renewable energy, implementing green manufacturing practices, and preventing deforestation from occurring [9]. The United States (U.S.) and Canada are the two most influential North American countries. GHG emissions from the U.S. energy industry are projected to decrease by about $28 \%$ from their 2007 value by 2030 . Canada also expects to reduce its GHG emissions by $30 \%$ from its 2005 level. Table 7 summarizes the types of combustion and primary feedstocks for both countries.

\section{Table 7}

Type of combustion and primary feedstocks used for the North American countries [9]

\begin{tabular}{lll}
\hline Country & Type of Combustion & Primary Feedstock \\
\hline USA & Direct & Wood pallets, wood chips, wood wastes, \\
& (pulverized coal-fired boiler) & railroad ties \\
Canada & Direct co-firing & $\begin{array}{l}\text { Agricultural products, forest residues, } \\
\text { domestic and municipal waste, and } \\
\end{array}$ \\
& & energy crops \\
\hline
\end{tabular}

\subsubsection{United States}

All biomass combustion in the U.S. uses direct co-firing, mostly a pulverized coal-fired boiler [9]. Wood products such as wood pellets, wood chips, and wood wastes are the primary feedstock for co-firing in almost $50 \%$ of plants in this country. Another source of biomass in the U.S. is railroad ties that used for co-firing. Currently, 40 out of the 560 coal-fired thermal power plants in the U.S. use biomass co-combustion technologies. This number is expected to increase in the future.

\subsubsection{Canada}

Canada is one of the global leaders in pellet production, and its utilisation in co-firing would be a major contributor to electricity generation and GHG emissions reduction. The majority of biomass co-firing power plants in Canada are direct co-firing. In 2014, Canada has around 70 biomass powers 
with total capacity of $2500 \mathrm{MW}$. The primary feedstocks for co-firing include agricultural products, forest residues, domestic and municipal waste, and energy crops.

\subsection{South America}

Biomass co-firing is not common in South America compared to Europe, considering the abundance of biomass resources. However, the possibilities for biomass co-firing in this region is very promising. For example, Brazil is one of the world's largest producers of agricultural waste (such as soy, corn, rice, manioc, wheat, cotton, beans, and sugarcane) yet still use coal to generate electricity.

Despite its huge potential, Brazil's main agricultural residue producing areas are still far from existing coal-fired power plants [9]. Therefore, it is not economically feasible to introduce co-firing in coal-fired power plants. Building a biomass power plant in a region rich in agricultural residues is one potential solution to this problem. In this case, the government needs to establish a strong strategy to resolve the seasonality and volatility of raw materials.

\subsection{Asia}

Some Asian countries such as Japan, China, and South Korea have already adopted co-firing technologies. Biomass production and trade have also increased in countries where new investors are increasingly investing in co-firing biomass. In these regions, wood pellets co-fired with coal are considered the main source of electricity production.

Twelve coal-fired thermal power plants in Japan have started co-firing test runs or commercial co-fired power generation [9]. Forest residues are mainly used by these plants, with a biomass or coal mixing rate of 2 to $3 \%$. Although some smaller plants use gasifier, most plants in Japan use biomass in their existing coal mill.

\section{Feedstock Characteristics for Thermal Power Plant Combustion}

Biomass co-firing in coal-fired boilers introduces different types of fuels into the boiler. Several variables need to be considered when coal biomass is co-fired, as biomass's physical and chemical properties may cause some challenges when feeding higher biomass percentages in the boiler [13]. Furthermore, it is necessary to understand the biomass characteristics to prevent potential problems such as slagging, fouling and early combustion than coal. The most important biomass characteristics, including palm oil waste, will be explained in detail in this section.

\subsection{Heat value}

One of the most important fuel characteristics is the heat value or the amount of heat contained in a fuel $(\mathrm{kJ} / \mathrm{kg})$. Heat value shows the total amount of energy available in the fuel. The heat value can be represented in either higher heating value (HHV) or lower heating value (LHV) [16].

The HHV, also known as the gross calorific value (GCV), can be measured experimentally with an adiabatic calorimeter in the laboratory. The difference in GCV of biomass waste is shown in Figure 1. The lowest gross calorific value of biomass waste is wood at $11.86 \mathrm{MJ} / \mathrm{kg}$, followed by switchgrass, corn stover, EFB PMF and PKS. The gross calorific value of the palm oil wastes is higher than wood, switchgrass, and corn stover. Higher GCV is preferable because it indicates the higher energy content of biomass. 


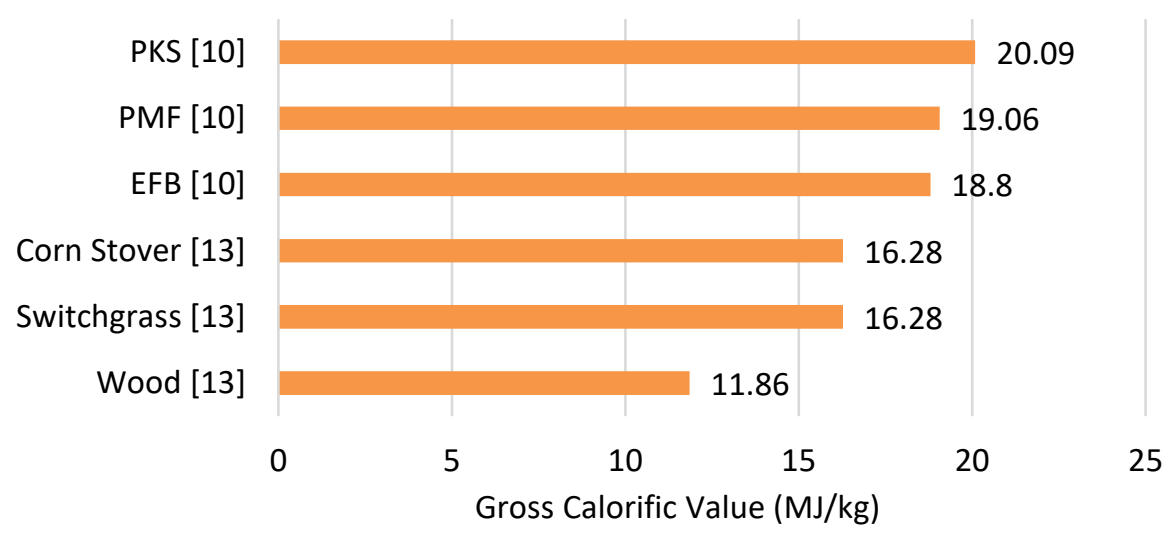

Fig. 1. Gross calorific value (M.J./kg) of biomass waste

\subsection{Moisture and Volatiles Content}

The characteristics of biomass, such as high moisture and volatile content, influence the grinding, feeding and combustion behaviour during combustion. For example, the higher moisture content can limit the capacity of grinders when biomass is co-milled with coal for co-firing. In addition, the higher moisture content will reduce the maximum temperature of combustion and increase the time taken for the feedstock to remain in the combustion chamber. As a result, it will lead to incomplete combustion and increases emissions [13].

Figure 2 shows the moisture and volatile content of PKS, PMF, EFB, corn stover, switchgrass, and wood. EFB has the most moisture and volatile content than the other biomass wastes. For the efficiency of the thermochemical process, it is important to keep the moisture content of the biomass as low as possible because the high moisture content of the biomass will result in drying costs [18]. In addition, it is also essential to have a low concentration of volatile matter and high activation energy of biomass waste to prevent early combustion and volatile oxidation.

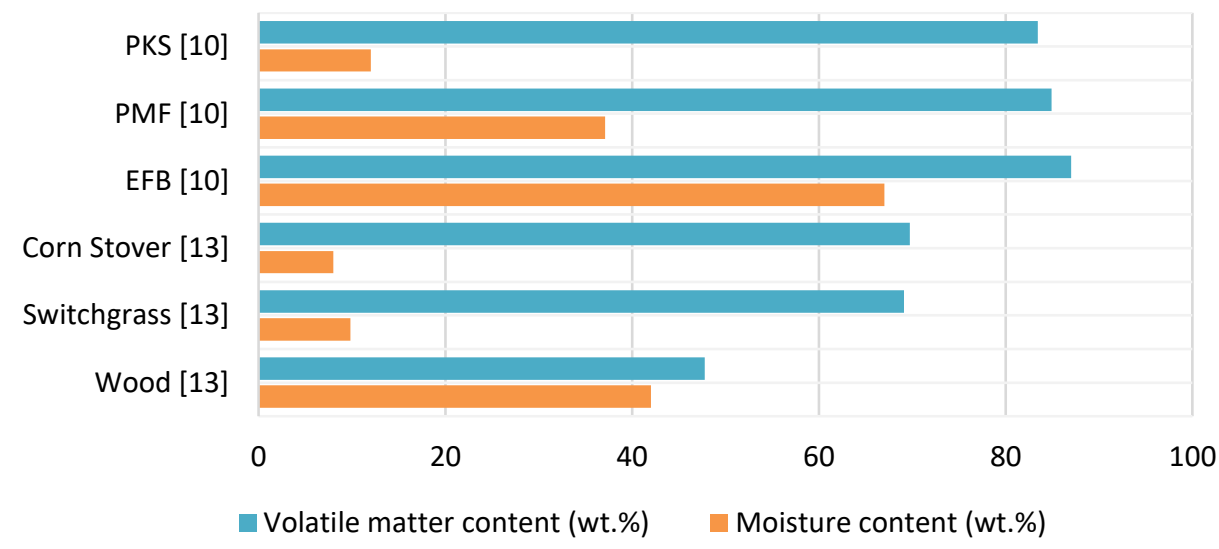

Fig. 2. Moisture and volatile content (wt.\%) of biomass waste

Biomass particles are usually more reactive due to their higher volatile content compared to coal. A previous study has shown that most of the energy produced by biomass combustion comes from the reaction of volatile matter, while in the case of coal, the energy comes from char oxidation [13].

In Malaysia, PKS and PMF are widely used as a fuel without pretreatment in boilers to generate electricity in oil palm mills because of the high calorific value and low moisture content [18]. Since oil palm waste is one of Malaysia's most abundant agricultural waste, it is worth utilising the wastes as a potential source of co-firing feedstock. 


\subsection{Chemical Composition}

The difference in characteristics of coal and biomass make it challenging to produce solid fuel for co-firing. Another issue is the ash composition in the biomass, resulting in the formation of slags and fouling in the boiler [18]. Generally, woody biomass contains less ash than coal. The ash composition produced by chemical components is needed for plant growth, while coal ash reflects mineral composition [13].

Harmful substances such as heavy metals can also be found in biomass ash. In addition, operational problems in the boiler like slagging and fouling can cause when the alkali or alkaline matter, namely potassium (K), sodium $(\mathrm{Na})$, magnesium $(\mathrm{Mg})$, and calcium $(\mathrm{Ca})$ when reacting with silica (Si) [18]. At the same time, biomass ash characterization is by a significant diversification of properties depending on the type of biomass burned and its sources [19].

Figure 3 shows the ash contents in biomass waste compared to coal. Although the ash content of biomass is much lower than in coals, its different composition and chemical nature influence the operation of boiler machinery, which induces increased accumulation of slag and ash in the furnace or increased wear of metal boiler components due to corrosion [19].

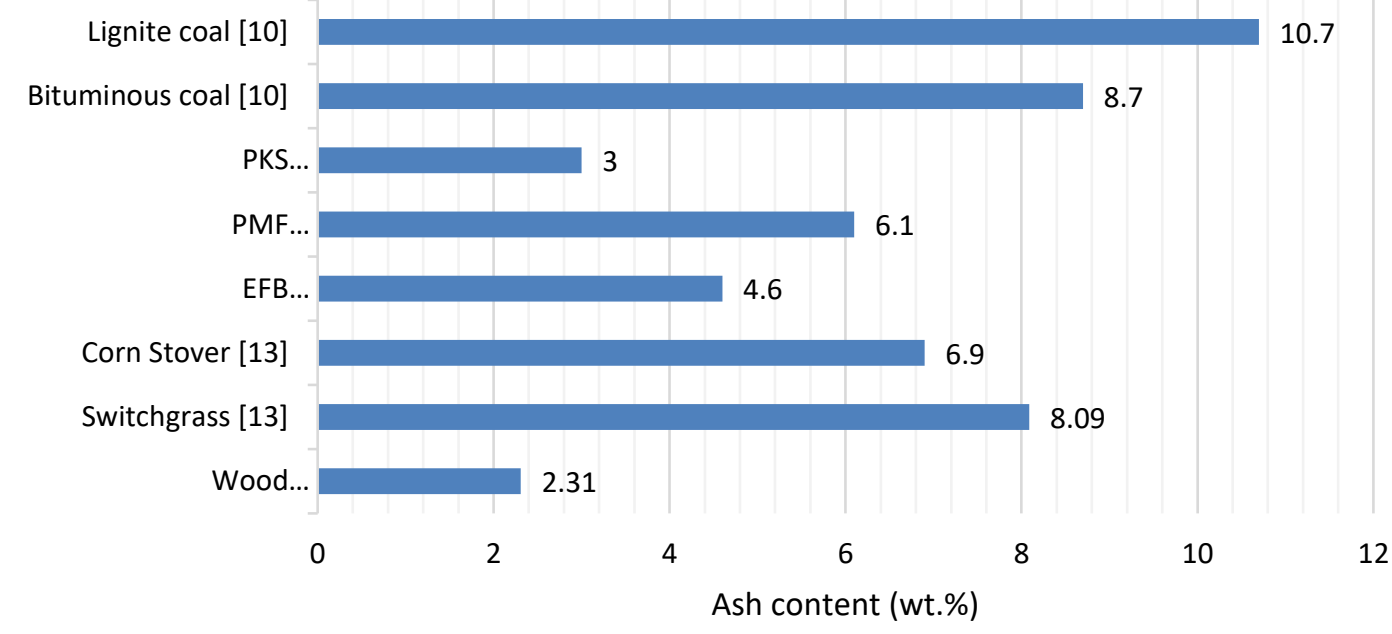

Fig. 3. Ash content (wt.\%) of biomass waste and coal

These problems can lead to increased operating costs and reduced device performance and availability. These characteristics need to be uniform to effectively co-fire different types of biomasses at higher percentages without losing boiler efficiency.

\subsection{Fuel Size and Density}

According to previous studies by Tumuluru et al., [13], the quantity of biomass that can combust with coal depends on physical properties such as bulk density, distribution of particle size, moisture content, and unrestricted yield strength. Biomass particles are naturally large, with varying size, shape and density. Therefore, for co-firing purposes, the biomass must be densified. Low bulk density and uneven distribution of particle size include the physical property limitations of biomass for cofiring with coal. Biomass densification can be done using pellets mills, screw extruders, or briquette presses [13]. This densified biomass can be adapted to the existing boiler design with little or no modification.

One of the most critical keys to an effective co-firing process is to size the biomass appropriately and consistently according to the parameters of the type of boiler used. Biomass that does not meet 
these specifications may cause flow problems in fuel processing equipment or incomplete burnout in the boiler. The general biomass size requirements for each type of boiler mentioned here are presented in Table 8 [20].

Table 8

Biomass sizing requirements [20]

\begin{tabular}{ll}
\hline Existing Type of Boiler & Size Required $(\mathrm{mm})$ \\
\hline Pulverized coal & $\leq 6.35$ \\
Stoker & $\leq 76.2$ \\
Cyclone & $\leq 12.7$ \\
Fluidized bed & $\leq 76.2$ \\
\hline
\end{tabular}

\section{Required Process for Co-firing Palm Oil Wastes}

The difference in biomass and coal properties makes it challenging to produce solid fuels for cofiring with coal. As biomass has high moisture contents, which will result in incomplete combustion, and the presence of alkali and alkaline elements like potassium $(\mathrm{K})$, chlorine $(\mathrm{Cl})$, and sodium (Na) concentrations may cause problems associated with ash deposition, corrosion, slagging, and fouling inside the combustor [18].

Therefore, few biomass pretreatments have been developed before combustion with coal and address different biomass characteristics such as leaching or washing, torrefaction, and hydrothermal treatment (HTT) [13]. Leaching/washing is one of the effective methods to reduce the alkali and alkaline matter by washing the biomass with water or acid. Meanwhile, the torrefaction process will reduce biomass moisture as this process is conducted in the absence of oxygen, at a temperature of 200 to $300^{\circ} \mathrm{C}$ for residence times of 60 mins. Hydrothermal pretreatment (HTT) is also known as hydrothermal carbonization and wet torrefaction [21]. This pretreatment involves hot compressed water to treat biomass at different temperatures below $260^{\circ} \mathrm{C}$, which is slightly lower than torrefaction. This treatment can increase the $\mathrm{CV}$ and improve the drying performance.

The biomass pretreatment includes converting it into a shape incorporated into the generation plant's fuel chain without much modification to the plant itself. However, palm oil wastes like PKS and PMF are widely used as fuels to generate electricity in the oil palm mills without pretreatment in the boilers due to the high CV and low moisture content of PKS and PMF.

Nevertheless, thermal pretreatment of EFB is required to be considered as a good fuel. A commercial-scale study of EFB, which was conducted using HTT, has increased the CV and reduced the chlorine content. As compared to raw EFB, the volatile matter also decreased [18]. HTT of EFB also reduces the moisture content to approximately $3 \%$, improving the drying performance as raw EFB is known for its high moisture content, around $65-67 \%[5,22]$.

Pelletization of EFB is one of the solutions intended to enhance its physical properties for valueadded applications. Besides, this palletization will greatly lower production costs, mostly for raw materials, transport, and storage. The pretreatment of EFB as a feedstock for pellet production involves five steps, namely, press with shredder, sieving, second-stage shredding, drying, and grinding, which can effectively reduce the size and moisture content, as in Figure 4 [23].

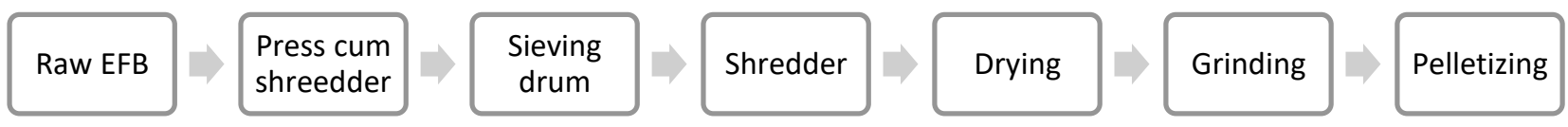

Fig. 4. Flow diagram of pretreatments for EFB pelletization 


\section{Potential of Energy Generation and GHG Reduction}

Biomass can provide a great solution for deforestation and greenhouse gas (GHG) emissions. Many advanced countries are working on reducing the emissions of GHGs associated with fossil fuel combustion. Governments in different countries are attempting to implement various policies and to include subsidies to promote the use of biomass in the energy sector [9]. Over the years, some biomass power plants have begun operations in Malaysia, and their target is to reduce GHG emissions.

The palm oil industry in Malaysia leaves behind an enormous amount of biomass from its plantation and milling operations, as shown in Table 9, which is much higher relative to other biomass types [26]. A previous study also found out that palm oil biomass has the potential to make Malaysia one of the contributors to renewable energy [27]. Moreover, it is practically possible to transform oil palm biomass into a wide variety of value-added products, classified into three major groups: biobased value-added products (such as bio-plastic, pulp and paper products from EFB), bio-fuel, and direct fuel for electricity generation [26].

Table 9

Biomass potential for power generation in Malaysia [26]

\begin{tabular}{llll}
\hline Biomass Type & $\begin{array}{l}\text { Quantity, } \\
\text { Ktonne/year }\end{array}$ & $\begin{array}{l}\text { Annual Generation } \\
\text { Potential, GWh }\end{array}$ & $\begin{array}{l}\text { Maximum Energy } \\
\text { Potential, MW }\end{array}$ \\
\hline EFB & 16,700 & 28,000 & 3,150 \\
PMF & 12,200 & & \\
PKS & 4,900 & & 320 \\
POME & 38,900 & 2,800 & 70 \\
Wood Chips & 2,200 & 600 & 30 \\
Rice Husks & 400 & 300 & 25 \\
Bagasse & 300 & 200 & 3,595 \\
TOTAL & 58,500 & 31,900 & \\
\hline
\end{tabular}

Palm oil waste, such as EFB, PMF, and PKS, can produce steam for processing and generating electricity. The basic pretreatment process is required for the effective use of palm oil waste due to their properties, e.g., a drying process to reduce the moisture content and a shredding machine to reduce the size of EFB [24].

Other than that, the oil palm tree is known as a carbon-neutral element because when it's going through a combustion process or decomposition process, the number of carbons emitted into the atmosphere is equivalent to what they have absorbed $[6,13]$. Therefore, it is noteworthy that this biomass is a sustainable source of raw materials and energy. Palm oil has also been in the spotlight as an alternative bioenergy source to solve fossil fuel problems. In addition, it has been proven to be a potential alternative to reduce the negative environmental impact of global warming due to its environmentally friendly nature [25].

As a result of the implementation of renewable energy and energy efficiency technologies, it has been discovered that these alternative scenarios offer sufficient electrical power to the sectors involved (i.e., residential, industrial, and commercial sectors). It also can reduce the emission of GHG and prolong the life of fossil fuel reserves [27].

\section{Conclusions}

Combustion of biomass in a thermal power plant is a promising alternative to reduce greenhouse gas (GHG) emissions and minimize biomass wastes related to its disposal. Most of the existing co- 
firing biomass in other countries are using wood pellets in their boiler. However, due to the lack of biomass resources in some countries such as Denmark, increased demand for biomass can negatively impact the economy.

The utilisation of palm oil waste in Malaysia is a key factor in providing a long-term approach to Malaysia's energy needs and supporting sustainable development. Palm mesocarp fiber (PMF) and palm kernel shells (PKS) are commonly used in oil palm mills as fuel without pretreatment due to their high heating value and low moisture content. However, for EFB, it is required to do some pretreatment followed by densification to modify the physical and chemical properties. The pretreatment will result in significant changes in reducing the moisture content and increasing the calorific value of EFB.

Subsequently, Malaysia has the potential to be one of the world's major contributors to renewable energy by the usage of palm oil waste. In addition, reducing GHG emission and the cost of imported fossil fuel by substituting fossil fuels with EFB, PKS, and PMF will benefit Malaysia in terms of economic and environmental. Therefore, further research and development must be carried out in the power generation industry.

Because of the abundance of palm oil residues in Malaysia, it will be interesting to see the country adapts to direct biomass combustion in the near future. When using the direct co-firing method, only minor modifications to the storage and feeding systems are needed. However, several technical issues need to be addressed for co-fired palm oil residues, such as boiler performance when adding new fuel to the existing boiler and the cost of logistics since palm oil mills are majorly located in rural areas. Emissions, ash deposition, and corrosion were among the boiler performance problems highlighted.

In addition, the authorities are expected to implement other alternatives to make biomass combustion in thermal power plants more feasible in this country. Relevant RE policy measures must be established to ensure reliable biomass energy in the future.

\section{Acknowledgement}

This research was funded by a grant from the AAIBE Chair of Renewable Energy, Institute of Sustainable Energy, Universiti Tenaga Nasional.

\section{References}

[1] Field, Christopher B., and Vicente R. Barros, eds. Climate change 2014-Impacts, adaptation and vulnerability: Regional aspects. Cambridge University Press, 2014.

[2] Ismail, H., A. A. Aziz, R. A. Rasih, N. Jenal, Z. Michael, and Azmi Roslan. "Performance of organic Rankine cycle using biomass as source of fuel." Journal of Advanced Research in Applied Sciences and Engineering Technology 4, no. 1 (2016): 29-46.

[3] Ozturk, Munir, Naheed Saba, Volkan Altay, Rizwan Iqbal, Khalid Rehman Hakeem, Mohammad Jawaid, and Faridah Hanum Ibrahim. "Biomass and bioenergy: An overview of the development potential in Turkey and Malaysia." Renewable and Sustainable Energy Reviews 79 (2017): 1285-1302. https://doi.org/10.1016/j.rser.2017.05.111

[4] George, Bill. "Oilseeds: World Markets and Trade." Foreign Agricultural Service, August 12, 2021. https://www.fas.usda.gov/data/oilseeds-world-markets-and-trade.

[5] Salleh, Siti Fatihah, Adlansyah Abd Rahman, and Tuan Ab Rashid Tuan Abdullah. "Potential of Deploying Empty Fruit Bunch (EFB) for Biomass Cofiring in Malaysia's Largest Coal Power Plant." In 2018 IEEE 7th International Conference on Power and Energy (PECon), pp. 429-433. IEEE, 2018. https://doi.org/10.1109/PECON.2018.8684124

[6] Awalludin, Mohd Fahmi, Othman Sulaiman, Rokiah Hashim, and Wan Noor Aidawati Wan Nadhari. "An overview of the oil palm industry in Malaysia and its waste utilization through thermochemical conversion, specifically via liquefaction." Renewable and Sustainable Energy Reviews $50 \quad$ (2015): 1469-1484. https://doi.org/10.1016/i.rser.2015.05.085

[7] European Biomass Industry Association. "Operational Problems In Biomass Combustion." EUBIA, 2021. https://www.eubia.org/cms/wiki-biomass/combustion/operational-problems-in-biomass-combustion/. 
[8] IEA. "Co-utilisation of Biomass with Fossil Fuels". IEA Bioenergy, 2013. https://www.ieabioenergy.com/wpcontent/uploads/2013/10/Co-Utilisation-of-Biomass-with-Fossil-Fuels-Summary-and-Conclusions2.pdf.

[9] Roni, Mohammad S., Sudipta Chowdhury, Saleh Mamun, Mohammad Marufuzzaman, William Lein, and Samuel Johnson. "Biomass co-firing technology with policies, challenges, and opportunities: A global review." Renewable and Sustainable Energy Reviews 78 (2017): 1089-1101. https://doi.org/10.1016/j.rser.2017.05.023

[10] Basu, Prabir. Biomass gasification, pyrolysis and torrefaction: practical design and theory. Academic Press, 2018. https://doi.org/10.1016/B978-0-12-812992-0.00007-8

[11] Tillman, David A. "Biomass cofiring: the technology, the experience, the combustion consequences." Biomass and Bioenergy 19, no. 6 (2000): 365-384. https://doi.org/10.1016/S0961-9534(00)00049-0

[12] Xu, Yan, Kun Yang, Jiahui Zhou, and Guohao Zhao. "Coal-biomass co-firing power generation technology: Current status, challenges and policy implications." Sustainability 12, no. 9 (2020): 3692. https://doi.org/10.3390/su12093692

[13] Tumuluru, Jaya Shankar, J. Richard Hess, Richard D. Boardman, Christopher T. Wright, and Tyler L. Westover. "Formulation, pretreatment, and densification options to improve biomass specifications for co-firing high percentages with coal." Industrial Biotechnology 8, no. 3 (2012): 113-132. https://doi.org/10.1089/ind.2012.0004

[14] Khattak, Muhammad Adil, Mohammad Azfar Haziq Ayoub, Muhammad Ariff Fadhlillah Abdul Manaf, Mohd Faidhi Mahrul, Mohd Ridwan Mohd Juhari, Mira Idora Mustaffa, and Suhail Kazi. "Global energy security and European Union: A review." Journal of Advanced Research in Applied Sciences and Engineering Technology 11, no. 1 (2018): 64-81.

[15] Khattak, Muhammad Adil, Nurul Syahrizzat Mohd Yasin, Hannah Natasha Andjani, Puteri Nurailah Husna Mohd Tajuddin, Sakeshraj Narajah, See Zhi Fei, Soh Ann Ting, and Suhail Kazi. "Global energy security and North America: A review." Journal of Advanced Research in Applied Sciences and Engineering Technology 11, no. 1 (2018): 82-98.

[16] Umar, H. A., S. A. Sulaiman, R. K. Ahmad, and S. N. Tamili. "Characterisation of oil palm trunk and frond as fuel for biomass thermochemical." In IOP Conference Series: Materials Science and Engineering, vol. 863, no. 1, p. 012011. IOP Publishing, 2020. https://doi.org/10.1088/1757-899X/863/1/012011

[17] Gravalos, Ioannis, Panagiotis Xyradakis, Dimitrios Kateris, Theodoros Gialamas, Dimitrios Bartzialis, and Kyriakos Giannoulis. "An experimental determination of gross calorific value of different agroforestry species and bio-based industry residues." Natural Resources 7, no. 1 (2016): 57-68. https://doi.org/10.4236/nr.2016.71006

[18] Hamzah, Norfadhilah, Koji Tokimatsu, and Kunio Yoshikawa. "Solid fuel from oil palm biomass residues and municipal solid waste by hydrothermal treatment for electrical power generation in Malaysia: A review." Sustainability 11, no. 4 (2019): 1060. https://doi.org/10.3390/su11041060

[19] Zając, Grzegorz, Joanna Szyszlak-Bargłowicz, Wojciech Gołębiowski, and Małgorzata Szczepanik. "Chemical characteristics of biomass ashes." Energies 11, no. 11 (2018): 2885. https://doi.org/10.3390/en11112885

[20] Hayter, Sheila, Stephanie Tanner, K. Corner, and C. Demeter. "Biomass Cofiring in Coal-Fired Boilers." Federal Energy Management Program 5 (2004).

[21] Gil, María V., and Fernando Rubiera. "Coal and biomass cofiring: fundamentals and future trends." In New Trends in Coal Conversion, pp. 117-140. Woodhead Publishing, 2019. https://doi.org/10.1016/B978-0-08-102201-6.00005$\underline{4}$

[22] Darmawan, Arif, Dwika Budianto, Koji Tokimatsu, and Muhammad Aziz. "Analysis of Biomass Waste Cofiring into Existing Coal-Fired Power Plant Using Computational Fluid Dynamics." Computational Fluid Dynamics: Basic Instruments and Applications in Science (2018): 217. https://doi.org/10.5772/intechopen.70561

[23] Bakar, Nasrin Abu, Choo Yuen May, Joseph Lim, Stephen Lim, Eddy Chin, Soh Kheang Loh, Lim Weng Soon, and M. Yusman M. Yunus. "Improved process for the production of low-ash empty fruit bunch pellet." Selangor, Malaysia: Palm Oil Information Online Service 706, no. 4 (2015).

[24] Shuit, Siew Hoong, Kok Tat Tan, Keat Teong Lee, and A. H. Kamaruddin. "Oil palm biomass as a sustainable energy source: A Malaysian case study." Energy 34, no. 9 (2009): 1225-1235. https://doi.org/10.1016/i.energy.2009.05.008

[25] Mahlia, Teuku Meurah Indra, Norasyiqin Ismail, Nazia Hossain, and Arridina Susan Silitonga. "Palm oil and its wastes as bioenergy sources: a comprehensive review." Environmental Science and Pollution Research 26, no. 15 (2019): 14849-14866. https://doi.org/10.1007/s11356-019-04563-x

[26] Shamsuddin, Abd Halim. "Development of renewable energy in Malaysia-strategic initiatives for carbon reduction in the power generation sector." Procedia Engineering $49 \quad$ (2012): $384-391$. https://doi.org/10.1016/i.proeng.2012.10.150

[27] Samsudin, M. S. N., Md Mizanur Rahman, and Muhamad Azhari Wahid. "Sustainable power generation pathways in Malaysia: Development of long-range scenarios." Journal of Advanced Research in Applied Mechanics 24, no. 1 (2016): 22-38. 